\title{
ECOTURISMO, NATUREZA E HISTÓRIA: O CASO DO PARQUE NATURAL MUNICIPAL DA SERRA DO MENDANHA, RJ
}

\author{
José Lúcio Nascimento Júnior ${ }^{1}$ \\ Patrícia Maria Pereira do Nascimento
}

\section{RESUMO}

O estudo de revisão tem o objetivo de demonstrar que a atividade turística pode auxiliar na conservação do Parque Natural Municipal da Serra do Mendanha, no Município do Rio de Janeiro. Considerando a escassez de estudos sobre o Parque do Mendanha, utilizamos bibliografias sobre Ecoturismo e Turismo e Natureza publicados no Brasil na forma de artigos, capítulos e livros. Avaliou-se que o Ecoturismo no parque pode ser uma estratégia para impedir e/ou reduzir o desmatamento na Unidade de Conservação que sofre com a expansão residencial da comunidade do entorno, além das ações de posseiros, revelando que esta pode ser uma estratégia a ser utilizada na gestão da Unidade de Conservação.

Palavras chave: Unidade de conservação; Ecoturismo; Natureza e História.

\section{ABSTRACT}

The review study aims to demonstrate that tourism can assist in the conservation of the Municipal Natural Park of Serra do Mendanha, state of Rio de Janeiro. Because there are no studies on the Mendanha Park, we used studies on Ecotourism and Nature Tourism and published in Brazil in book form and chapter books. The possibility of using ecotourism as a way to prevent deforestation that the protected area suffers because of the expansion of the surrounding community and squatter actions, and shows that he can be a strategy to be used in protected area management .

Keywords: Conservation unit; Ecotourism; Nature and History.

\section{INTRODUÇÃO}

O turismo é um conjunto de serviços diversos para atender diferentes realidades e públicos. Enquanto atividade econômica encontra-se em expansão no Brasil, em especial no Rio de Janeiro. (COSTA: 2002; COSTA: 2013; TELES: 2011). Por ser um conjunto de serviços temos que partir de uma definição inicial para realizar o estudo. Assim,

Não podemos esquecer que o Turismo enquanto atividade se baseia em três elementos operativos: o tempo livre, o rendimento e as condições e sanções locais que permitem a atividade turística. $\mathrm{O}$ turismo pode ser entendido como um conjunto de técnicas baseadas em princípios científicos, as quais

\footnotetext{
${ }^{1}$ Licenciado em História pela SUAM, especialista em História Contemporânea pela UFF e em Educação Ambiental pelo SENAC. Docente da Gerência de Hospitalidade do SENAC Rio. E-mail: prof.joselucio@gmail.com

${ }^{2}$ Bacharel e Licenciada em Ciências Biológicas pela UNIGRANRIO. Especialista em Gestão Ambiental pela FTC. Docente da Gerência de Segurança e Saúde do SENAC Rio. E-mail: prof.pattynascimento@gmail.com.
} 
têm como objetivo prestar diferentes tipos de serviços às pessoas que utilizam seu tempo livre para viajar (ASSUNÇAO: 2013, p. 13).

Três pontos se colocam como importantes ao analisamos esta definição. O primeiro diz respeito ao deslocamento necessário à atividade; o segundo consiste na duração do deslocamento; e o terceiro, no fator motivador (ASSUNÇÃO: 2013). Considerando o terceiro ponto, o fator motivador, percebemos que este pode ser o mais diverso possível, tais como lazer, negócios, aventura, etc. (BOITEUX; WENER: 1999). Neste sentido, pode-se apresentar aos turistas uma grande variedade de atrativos.

Podemos dividir os atrativos turísticos em dois tipos: os atrativos naturais e os atrativos culturais (BOITEUX; WENER: 2009). Ligado aos atrativos naturais temos diversas formas de praticar o turismo, tais como: o turismo de aventura, o turismo rural, o ecoturismo, o turismo místico, o turismo de sol e mar e outros (TELES: 2011). No presente estudo, contudo, nos deteremos ao ecoturismo. Pensar o ecoturismo é pensar a apreciação a natureza e a preservação da natureza auxilia a pensar o ecoturismo. Neste sentido, esta modalidade de turismo nasce da vontade do ser humano em retornar e conhecer naturezas intocadas. (COSTA: 2002). Este segmento de turismo pode ser praticado em Unidades de Conservação (UC). Dentre as Unidades de Conservação mais conhecidas temos os Parques Nacionais, as Áreas de Proteção Ambiental e as Reservas Biológicas (COSTA: 2002).

Então, em que consiste o Ecoturismo? Partiremos inicialmente das definições apresentadas por Teles (2011) e Costa (2002) para iniciarmos esse debate.

Ecoturismo: é um segmento da atividade turística que utiliza, de forma sustentável, o patrimônio natural e cultural, incentiva sua conservação e busca a formaçãode uma consciência ambientalista através da interpretação do ambiente, promovendo o bem estar das populações (TELES: 2011, p. 9)

$\mathrm{O}$ ecoturismo é muito mais que isso: é, antes de mais nada, uma atividade que compreende em si um posicionamento ambiental de conservação do patrimônio natural e cultural, tanto em áreas naturais como em não naturais (COSTA: 2002, p. 15).

Ao se abordar o ecoturismo, consideramos o turismo que se vale do Patrimônio Cultural e/ou Ambiental para promover a consciência ecológica (COSTA: 2002). Propor o uso do ecoturismo como uma estratégia de conservação do Parque Natural Municipal da Serra do Mendanha (PNMSM) vem de encontro com o crescimento que a prática está experimentando no Brasil e com a perspectiva de se promover o desenvolvimento da consciência ambiental.

Em um primeiro momento, a natureza era vista como promotora de localidades, como algo que agregava valor ao produto turístico. Com o crescimento da atividade na década de 1970, houve a necessidade de maior sistematização. Buscou-se, então, criar métodos para medir a capacidade de carga, que era conhecida na época como capacidade de suporte (TELES: 2011). A sistematização do Ecoturismo, por sua vez, se iniciou no Brasil em 1987 com uma parceria entre a EMBRATUR e o IBAMA (COSTA: 2002). O fato em si estava relacionado também aos grandes eventos no Brasil e no mundo, tais como a Conferência de 
Estocolmo sobre o Meio Ambiente Humano (1972) o Relatório da Comissão Mundial de Ambiente e Desenvolvimento Humano (1987) e a ECO 92 (1992).

Na Rio+10 (2002), ocorreram discussões sobre o uso sustentável de unidades de recursos naturais. No Brasil, naquele mesmo ano, propôs-se a consolidação do Ecoturismo como prática de lazer e atividade econômica (COSTA: 2002). Sua ação se baseia no tripé da sustentabilidade, a saber: eficácia econômica, conservação ambiental e equidade social (COSTA: 2013). E a prática de sustentabilidade pode, ou não, estar na pauta de ações das operadoras e agências de viagens que executam a grande parte atividade turística no Brasil (NOGUEIRA: 2013).

A procura por esses locais, invariavelmente dotados de ecossistemas frágeis e/ou de grande importância ambiental, gera, por consequência, um contato com as Unidades de Conservação que protegem estas áreas, o que ocasiona, naturalmente, uma maior demanda por estes espaços (COSTA: 2002, p. 32). O turismo e, por conseguinte, o Ecoturismo, enquanto atividades econômicas trazem impactos positivos e negativos para o local utilizado como atrativo. A sua sustentabilidade liga-se a forma como o mesmo é realizado na comunidade local (COSTA: 2013). De acordo com Meneses temos que:

O turismo passa por um momento histórico em que, a despeito de ser um dos poucos setores da economia com possibilidades ainda ampliadas de crescimento, se vê em uma encruzilhada definidora de rumos bem distintos: ou se apresenta como uma proposta econômica de inclusão social e, assim, contribui para novas perspectivas de valorização da vida, do consumo de produtos culturais e de distribuição de renda, ou, por outro lado, alia-se a uma economia que exclui parcelas imensas da população da participação na produção e, dessa forma, opta por uma proposta de consumo de massa que pouco se preocupa com a sustentabilidade da produção econômica (MENESES: 2006, p. 13).

\section{MATERIAIS E MÉTODOS}

Para analisar as possibilidades do turismo no PNMSM foi realizada uma revisão de literatura. Como não existem pesquisas sobre o Ecoturismo no Parque do Mendanha, empreendeu-se a análise de livros e capítulos de livros que abordam o Ecoturismo e o Turismo e Natureza. Outro critério de escolha foi a utilização de bibliografias editadas após o ano 2000 como primeira edição. Esta escolha ocorreu com vistas a buscarmos materiais mais atualizados sobre o tema. Este recurso se justifica pelo fato da pesquisa ainda estar em seu momento inicial.

No levantamento inicial foram encontrados livros e capítulos de livros que tratam especificamente de Ecoturismo e de Ecoturismo em Unidades de Conservação. Estas bibliografias trazem um resumo de teorias e estudos de caso sobre os dois temas elencados anteriormente. Para facilitar a análise pesquisou-se adicionalmente uma tese de doutorado e um Trabalho de Conclusão de Curso sobre o Parque do Mendanha para obtenção de dados específicos sobre a UC. 
Partindo do conceito de Ecoturismo de Teles (2011) e Costa (2002) propôs-se que esta atividade se constituísse numa forma de: (1) integrar a população do bairro de Bangu e adjacências às atividades econômicas que estão em voga na atualidade, em especial o Turismo (2) impedir o desmatamento que a UC sofre por causa da ampliação da comunidade do entorno e de ações de posseiros e (3) inserir esta região nos roteiros turísticos uma vez que haverá grande movimentação de pessoas, seja por causa de sua proximidade com a Avenida Brasil, seja por ficarem próximo às novas instalações olímpicas que estão sendo construídas na região. Negar o potencial turístico do parque consiste em uma forma de negar a possibilidade de inclusão sócio-econômica dos moradores da Zona Oeste, em particular de binômio Campo Grande - Bangu, onde se localiza o Parque.

\section{RESULTADOS}

O Parque Natural Municipal da Serra do Mendanha se situa na Zona Oeste do Rio de Janeiro, abrangendo os bairros de Campo Grande e Bangu (Figuras 1 e 2). Sua administração é realizada pela Prefeitura Municipal da Cidade do Rio de Janeiro através da Secretaria Municipal de Meio Ambiente. Apesar de ser um Parque Natural, em seu entorno existem áreas habitacionais tanto em Bangu, como nos municípios de Mesquita e Nova Iguaçu. Outro fato importante consiste no fato de o Complexo Penitenciário de Bangu estar localizado nas proximidades (PONTES \& ROCHA: 2008; PONTES: 2010). Devido ao crescimento desordenado da Cidade e do entorno, em especial, áreas do Parque foram transformadas em local de plantio de jaqueiras e bananeiras (plantas exóticas na região), construção de espaços religiosos e comerciais, além de áreas de lazer, tais como clubes e sítios (NASCIMENTO: 2013).
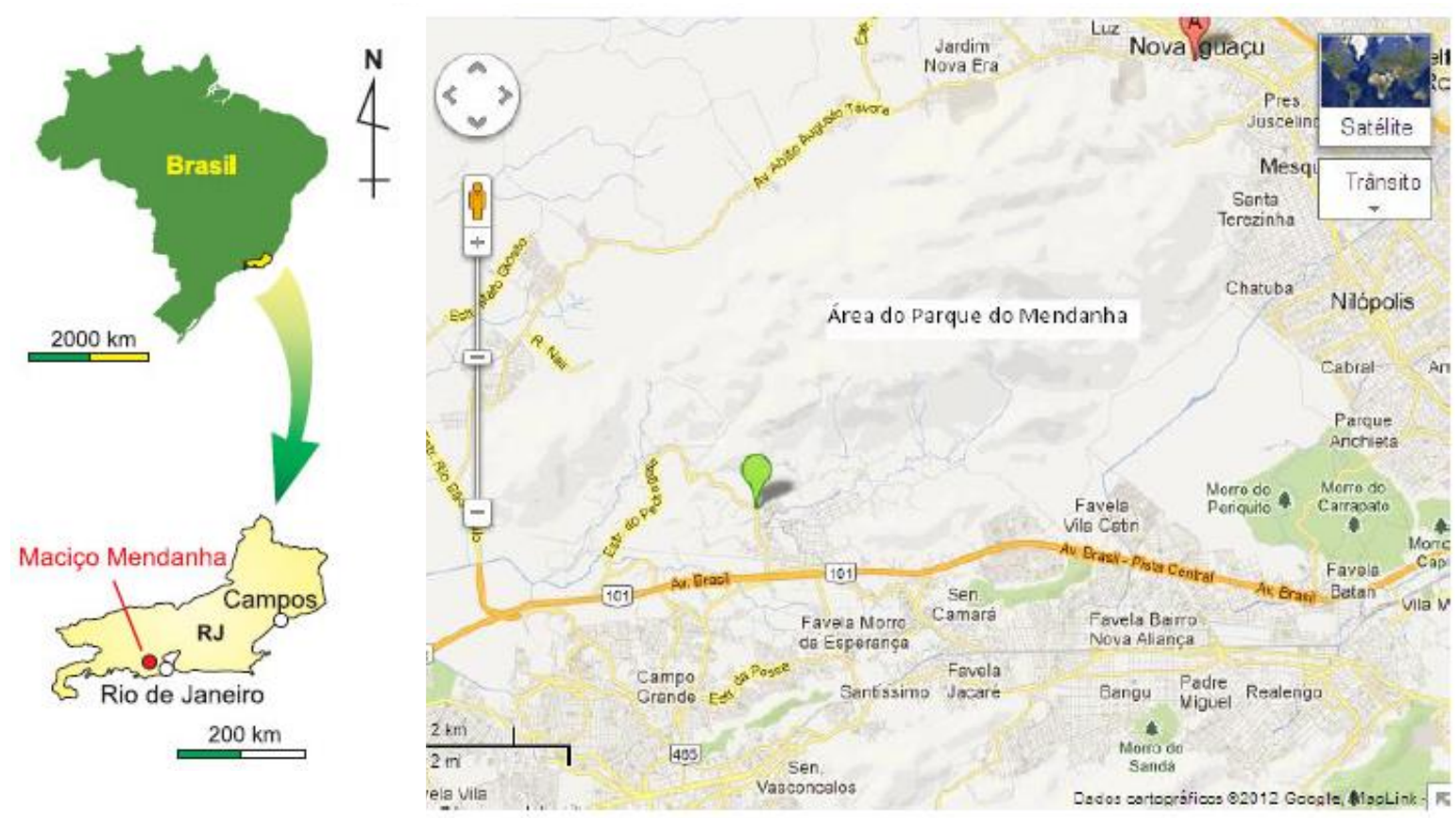

Figura 1. Localização do PNMSM. Fonte: NASCIMENTO: 2013, p. 4. (adaptado) 


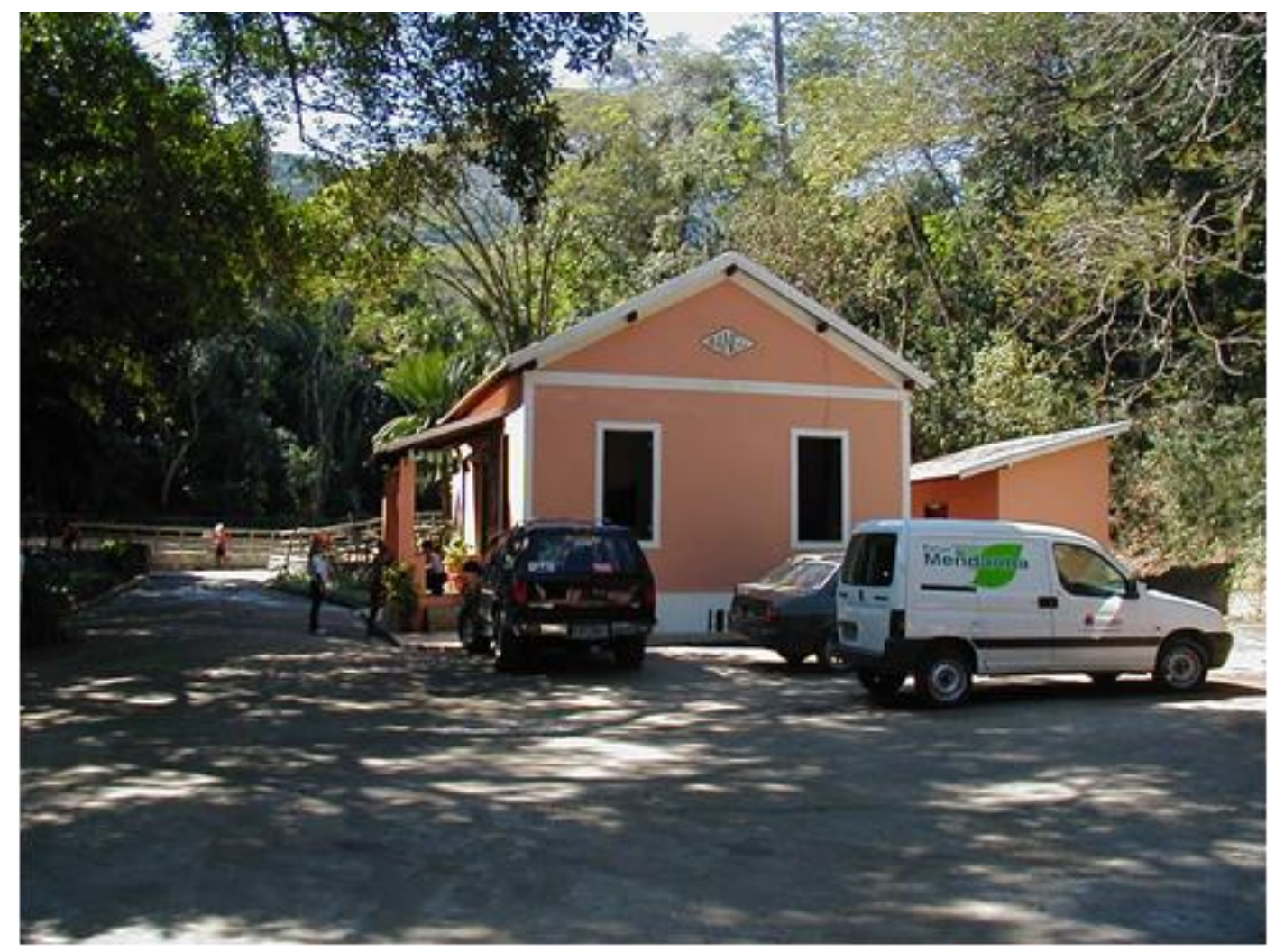

Figura 2. Guarita de entrada do Parque Natural Municipal da Serra do Mendanha Fonte: Arquivo pessoal Pontes, J. A. L., 2011

O Parque é uma UC criada por decreto municipal, mas que atende aos requisitos da legislação federal sobre o tema, Lei 9.985, de 18 de julho de 2000 (SNUC). Inicialmente, denominado Parque Ecológico do Mendanha, criado pela Lei Municipal 1.958 de 05 de abril de 1993. Porém, apenas em 2003, com o Decreto Municipal no 22.662, passou a ser chamado de Parque Natural Municipal da Serra do Mendanha. No período entre 1993 e 2003, a prefeitura permutou a área pertencente à antiga Fábrica de Tecidos Bangu, que ficava no mesmo local pertencente ao atual parque. Esta fábrica iniciou suas atividades no final do século XIX, sob o nome Companhia Progresso Industrial do Brasil, tendo suas atividades finalizadas no final do século XX, após quase um século de operação.

De acordo com Nascimento (2013) a proteção desta área pode trazer diversos benefícios à população local, tais como a melhoria na qualidade da água e do ar, além de espaços destinados a prática do Ecoturismo. Como ele já conta com espaços destinados ao lazer e entretenimento, incentivar seu uso como atrativo turístico pode ser uma forma de protegê-lo, pois este passaria a ser visto como algo importante pela comunidade circunvizinha (COSTA: 2002; COSTA: 2013; NOGUERIA: 2011). Para Costa (2002, p. 79) existem pontos positivos que a prática do Ecoturismo pode trazer para as Unidades de Conservação. 
Vejamos:

- $\quad$ gera emprego local;

- $\quad$ estimula rentáveis indústrias domésticas;

- diversifica a economia local;

- $\quad$ estimula o melhoramento dos serviços locais;

- $\quad$ melhora a compreensão e a comunicação entre diferentes culturas;

- $\quad$ proporciona financiamento a programas de áreas protegidas

- $\quad$ motiva o desenvolvimento de infra-estrutura para uso público de comunidades locais, assim como visitantes;

- demonstra o valor das áreas naturais em nível de tomada de decisões e na comunidade.

Além destes, ainda podemos citar:

- $\quad$ ganhos de divisas e créditos na balança de pagamentos em nível nacional;

- faturamento das empresas, tendo em vista a gama de negócios que servem ao turista;

- $\quad$ taxas e impostos para os governos;

- $\quad$ dinamização da economia;

- trabalho, emprego e renda pessoal, considerando que em locais bastante turísticos, grande parte dos trabalhadores tem renda vinculada a negócios do turismo, direta ou indiretamente, formal ou informalmente;

- efeito multiplicador econômico, entendido como uma medida de fluxo consequente de sucessivas rodadas de atividade econômica;

- $\quad$ estrutura de lazer para moradores, incrementada em razão da presença do turista, bem como infraestrutura básica (COSTA: 2013, p. 45 e 46).

Considerando as argumentações de Costa (2002) e Costa (2013), percebemos que pode haver um ganho significativo para as populações locais, assim como para o governo. Além disso, outras possibilidades poderiam ser citadas, mas sua enumeração tornaria este texto bem mais extenso.

Pensando a organização territorial da cidade, a ampliação da utilização do Parque do Mendanha como um atrativo turístico a ser consumido, para além da população local que o utiliza como espaço de lazer, pode interferir na especulação imobiliária e no ordenamento territorial e ambiental da cidade do Rio de Janeiro. Para a professora de Geografia Ana Fani Carlos, ao mesmo tempo em que o processo de reprodução do espaço "se submete cada vez mais ao jogo do mercado imobiliário (...) e das políticas estratégicas do Estado (...)”, temos que "o processo de reprodução espacial em uma grande metrópole é influenciado pelo desenvolvimento de uma nova atividade, produtiva, um novo ramo econômico: o turismo e o lazer" (CARLOS: 2012, p. 177 e 181).

Para além de questões econômicas, ainda podemos destacar que para José Meneses, "o turismo moderno, assim, emerge, também, de um ambiente romântico de descobertas e de 
construção de valores que buscam memorizar o passado, lembrá-lo, apreendê-lo, guardá-lo, co-memorá-lo" (MENESES: 2006, p. 13). O passado e/ou a natureza buscada pela atividade turística pode ser ressignificado a partir da transformação do local em um produto a ser consumido. E este produto a ser consumido é o patrimônio.

De acordo com François Hartog, desde a Convenção para a proteção do Patrimônio Mundial Cultural e Natural, de 1972, realizada pela UNESCO, cultura e natureza foram reunidas a partir de uma noção comum, o patrimônio. Hartog ainda nos chama a atenção para o " $e$ " contido no nome da convenção, este utilizado com a função de unificar as duas partes dentro de uma mesma noção, o patrimônio.

Dentre os espaços existentes no Parque do Mendanha temos: uma área de churrasqueiras, uma piscina e uma pequena área com trilha ecológica, além da sede do Parque e um espaço destinado a pesquisa, este parque conta com grandes possibilidades exploratórias no sentido de um espaço a ser consumido pelo visitante/turista. Um exemplo claro disto consiste no fato da piscina ser originalmente um reservatório de água da antiga fábrica. Este aspecto de descoberta de um passado memorável e um ambiente exótico pode ser mais um motivador da transformação do parque em um atrativo turístico, além dos fatores socioeconômicos apresentados anteriormente (Figura 3).

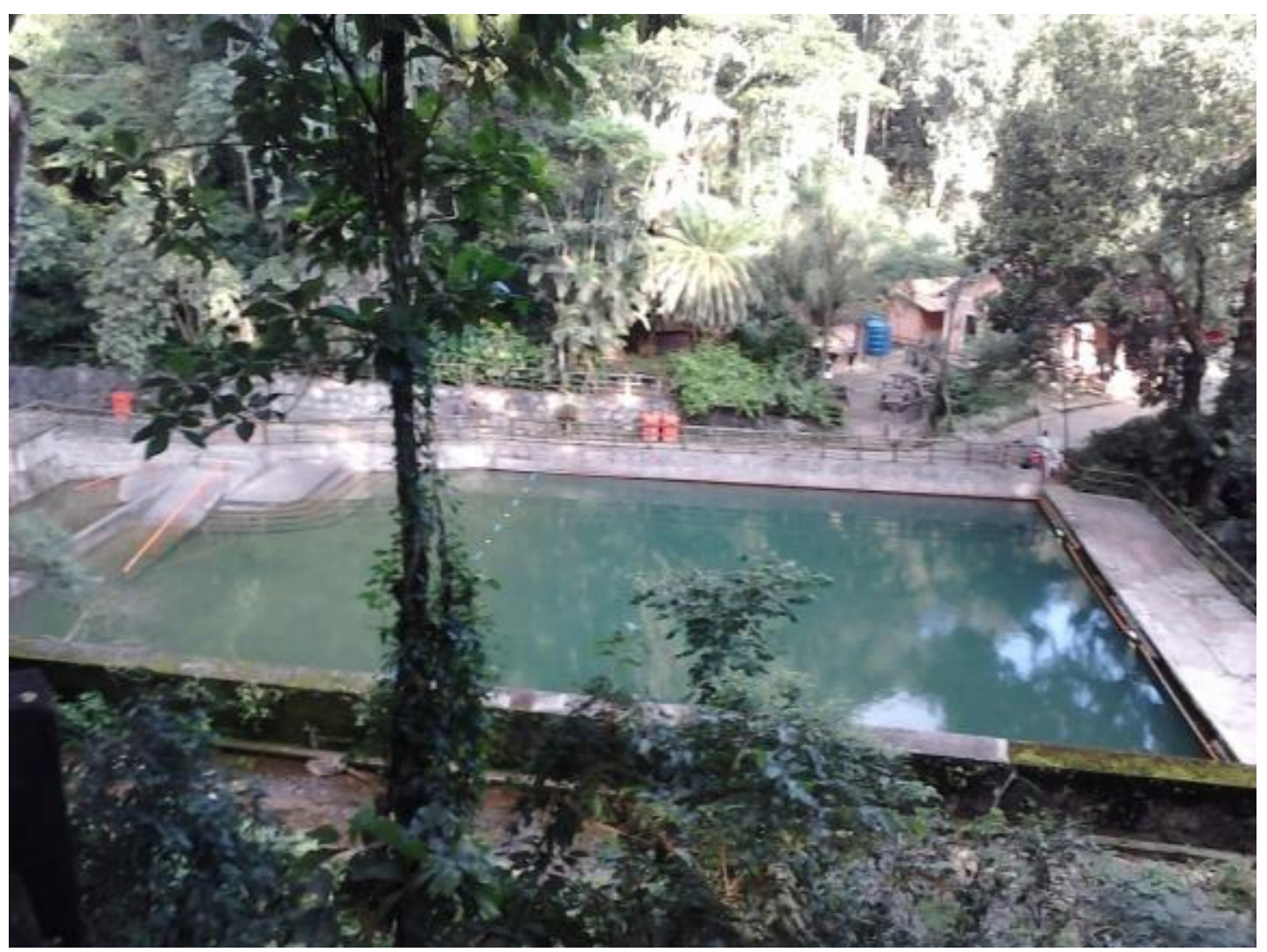

Figura 3. Antiga Caixa D’Água da Fábrica de Tecidos Bangu agora utilizada como piscina, área de Lazer para os visitantes. Arquivo dos autores, 2011 
A criação de um Espaço de Memória contando com materiais da Fábrica de Tecidos Bangu como, também, da riqueza de fauna e flora existentes no parque parece-nos um caminho fortuito para instigar a memória coletiva e atrair novos consumidores para este espaço. Seja pela ótica de turismo ou do lazer, a organização do Espaço de Memória pode auxiliar a criar uma nova Memória Coletiva a ser valorizada (HARTOG: 2014). A exposição de objetos do período da fábrica, assim como das riquezas naturais constitui-se como uma forma de trazer sentido para aquele que passar a visitar o Parque, seja como área de lazer, seja como produto turístico.

Nesta dualidade do patrimônio entre o Cultural e Natural, Hartog destaca que:

Ora, o meio ambiente foi qualificado como "patrimônio" a partir do momento em que se tomou consciência de que sua degradação, acidental ou comum (a poluição), temporária ou irreversível, engendrava no problema da transmissão. De onde emerge também uma primeira resposta: patrimonializar a natureza para se dotar de recursos jurídicos e assim poder preservá-la, desde hoje até amanhã (HARTOG: 2014, p. 196).

Assim, a riqueza da Mata Atlântica que o Parque do Mendanha possui pode se aliar ao seu passado a ser descoberto fazendo com que esta UC tenha seu valor no mercado turístico ampliado. "No contexto em que novas áreas adquirem valor de uso, o processo de apropriação passa a ser determinado pelas leis de mercado, isto é, definido pela sua trocabilidade. (...) Assim as particularidades dos lugares do espaço se afirmam, potencializadas pela produção, pois o uso só pode se realizar num determinado lugar, isto é, refere-se à escalada local (...)" (CARLOS: 2012, p. 179).

\section{CONCLUSÕES}

A criação do PNMSM como uma unidade de conservação em 2003 não garantiu a preservação da área, como podemos verificar pela degradação e desmatamento que ocorre no entorno (PONTES \& ROCHA: 2008; PONTES: 2010; NASCIMENTO 2013). Faz-se necessário, então, ampliar a visitação do Parque através da melhoria dos atrativos já existentes no mesmo. A valorização do espaço do parque como espaço de conservação e preservação da natureza e da história local, poderá ser o fator que modificará a relação das populações do entorno com a área preservada pela UC.

Indicamos, a partir da bibliografia consultada que o melhor modelo de implementação de atividade turística no referido parque consiste naquela que considera a inclusão da população do entorno nas atividades a serem desenvolvidas e não apenas como mão-de-obra ou um mal a ser superado. Comparando com o caso de Cabo Frio, apresentado por Boiteux e Wener (2003), a inclusão da população nas transformações promovidas pela prefeitura possibilitou que a cidade atingisse o potencial turístico que tem na atualidade. Ou seja, não bastam apenas as leis, o envolvimento direto da população consiste em fator de sucesso para a inserção do ambiente em local turístico. 


\section{BIBLIOGRAFIA}

BOITEUX, B.; WENER, M. Planejamento e Organização do Turismo. Rio de Janeiro: Qualimark, 2003.

CARLOS, A. O Consumo do espaço. in: CARLOS, A. (org.) Novos caminhos da Geografia. $6^{\circ}$ Ed. São Paulo, Contexto, 2012, p. 173 - 186.

COSTA, H. Destinos do turismo: percursos para a sustentabilidade. Rio de Janeiro: FGV, 2013.

COSTA, P. Ecoturismo. São Paulo: Aleph, 2002.

DUARTE, R. História e Natureza. 2. ed. Belo Horizonte: Autêntica, 2013.

HARTOG, F. Regimes de historicidade: presentismo e experiências do tempo. Belo Horizonre: Autêntica, 2014.

MENESES. J. História e Turismo Cultural. Belo Horizonte: Autêntica, 2006.

NASCIMENTO, P. Controle e manejo de plantas exóticas: estudo de caso das jaqueiras (ArtocarpusHeterophylusLam.) sobre os anuros e artrópodes na Serra do Mendanha, rio de Janeiro, RJ. Salvador: TCC apresentado a FTC, 2013.

NOGUEIRA, S. Ações sustentáveis para o desenvolvimento do ecoturismo em unidade de conservação. In: TELES, R. Turismo e meio ambiente. Rio de Janeiro: Elsevier, 2011, p. 61 $-86$.

PONTES, J. A. L. A Riqueza e diversidade de anfíbios anuros da Serra do Mendanha, Estado do Rio de Janeiro: grau de conservação da floresta, variação altitudinal e uso de recursos hídricos. RJ: Tese de Doutorado - UERJ, 2010.

PONTES, J. A. L.; ROCHA, C. Serpentes da Serra do Mendanha. Rio de Janeiro: Technical Books, 2008.

TELES, R. Turismo e meio ambiente ou turismo da natureza? Alguns apontamentos para organização dessa modalidade. in: TELES, R. Turismo e meio ambiente. Rio de Janeiro: Elsevier, 2011, p. 03 - 20. 